\title{
6 OPEN ACCESS \\ Implementation of the FIFA 11+ football warm up program: How to approach and convince the Football associations to invest in prevention
}

\author{
Mario Bizzini, Astrid Junge, Jiri Dvorak
}

Medical Assessment and Research Centre, and Schulthess Clinic, Zurich, Switzerland

Correspondence to Mario Bizzini, Medical Assessment and Research Centre, FIFA-Strasse 20, PO Box 8044 Zurich 8008, Switzerland;

Mario.Bizzini@F-MARC.com

Accepted 8 May 2013

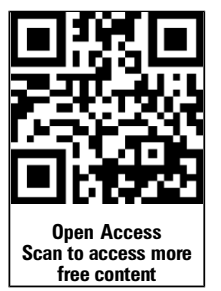

To cite: Bizzini M, Junge $A$, Dvorak J. Br J Sports Med 2013:47:803-806

\begin{abstract}
In the last decade, injury prevention has received a lot of attention in sports medicine, and recently international sports-governing bodies, such as the International Olympic Committee, declared the protection of the athletes' health as one of their major objectives. In 1994, the Fédération Internationale de Football Association (FIFA) established its Medical Assessment and Research Centre (F-MARC) with the aim 'to prevent football injuries and to promote football as a healthenhancing leisure activity, improving social behaviour'. Since then, FIFA has developed and evaluated its injuryprevention programmes 'The 11' and 'FIFA 11+' have demonstrated in several scientific studies how simple exercise-based programmes can decrease the incidence of injuries in amateur football players. This paper summarises 18 years of scientific and on-field work in injury prevention by an international sports federation (FIFA), from formulating the aim to make its sport safer to the worldwide dissemination of its injury-prevention programme in amateur football.
\end{abstract}

\section{INTRODUCTION}

Football is played on an amateur or recreational level by almost 300 million people all over the world. ${ }^{1}$ Besides being a healthy leisure activity, football, as a contact team sport, has a certain risk of injury. The medical treatment of football-related injuries could have a significant socioeconomic impact: for example, in Switzerland (with 7.9 million inhabitants), the healthcare costs for football injuries were nearly US $\$ 170$ million in $2010 .^{2}$

There is extensive literature on the frequency and characteristics of football injuries, ${ }^{3-7}$ and several scientific studies on injury-prevention programmes in amateur football players have been published. ${ }^{8-25}$ However, the implementation of injury-prevention programmes in the real world of sports represents a major challenge. ${ }^{26}{ }^{27}$ However the effectiveness of countrywide campaigns to reduce the incidence of football injuries has been proven. $^{28} 29$

In 1994, Fédération Internationale de Football Association (FIFA) founded its Medical Assessment and Research Centre (F-MARC) in order to create and disseminate scientific knowledge on various medical topics in football, to reduce football injuries and to promote football as a health-enhancing leisure activity.

Eighteen years later, this paper summarises the historical background, development, scientific evaluation and dissemination strategies of FIFA's injury-prevention programmes ('FIFA 11+') in order to provide a model of how an international sports federation can make its sport safer.

Development of injury-prevention programmes

The first scientific study on injury prevention in football was Jan Ekstrand's thesis in the 1980s. ${ }^{30}$ For about 20 years, no other author published a research paper on the prevention of football injuries in general, and only a few studies investigated the prevention of recurrent ankle sprains ${ }^{18} 2122$ and/or severe knee injuries. ${ }^{19}{ }^{31}$ In 2000, Heidt et $\mathrm{al}^{12}$ showed that the 42 female players who participated in the Frappier Acceleration Training Programme had less time-loss injuries than the control group. At the same time, F-MARC conducted its first study on the prevention of football injuries showing $21 \%$ fewer injuries in the intervention compared with the control group. ${ }^{13}$ The interventions were focused on improving the structure and content of the training by educating and supervising the coaches and players. The programme included preventive interventions such as improvement of warm-up, regular cool-down, taping of unstable ankles, adequate rehabilitation, promotion of the spirit of fair play and 10 sets of exercises designed to improve coordination, stability of the ankle and knee, flexibility and strength of the trunk, hip and leg muscles. On the basis of the experiences with this pilot study and in cooperation with international experts, F-MARC developed a basic injury-prevention programme for amateur football players called 'The 11'.

'The 11' comprises 10 evidence-based or bestpractice exercises (core stability, balance, dynamic stabilisation and eccentric hamstring strength) and the promotion of fair play. The programme was designed to reduce the most common football injuries (ankle and knee sprains, hamstring and groin strains). It can be completed in $10-15 \mathrm{~min}$ and requires no equipment other than a ball. 'The 11' was implemented in two countrywide campaigns (Switzerland and New Zealand) in cooperation with the national accident insurance company and the national football association. ${ }^{28} 29$

In Switzerland, the implementation of 'The 11' and its effect on the injury rate were carefully evaluated by an independent research company. ${ }^{29}$ Four years after the launch of the programme, teams that included 'The 11' as a part of their warm-up had $11.5 \%$ fewer match injuries and $25.3 \%$ fewer training injuries than teams that warmed up as usual. In New Zealand, the implementation of 'The 11 ' resulted in a 2.4 dollars of return of investment for the national accident insurance company after 
2 years. ${ }^{28}$ In a randomised controlled trial (RCT) conducted by the Oslo Sports Trauma and Research Center (OSTRC), the compliance of the intervention group was too poor for a statistically significant effect of the programme. ${ }^{32}$

On the basis of the experiences with 'The 11', 'PEP' (Prevent Injury and Enhance Performance programme) ${ }^{10} 16$ and other exercise-based programmes ${ }^{12} 193133$ to prevent football injuries, an advanced version ('FIFA 11+') was developed in 2006 together with OSTRC and the Santa Monica Orthopaedic and Sports Medicine Research Foundation. 'FIFA 11+' is a complete warm-up programme with running exercises at the beginning and end to activate the cardiovascular system, and specific preventive exercises focusing on core and leg strength, balance and agility, each of three levels of increasing difficulty to provide variation and progression. It takes about $20 \mathrm{~min}$ to complete, and requires a minimum of equipment (a set of cones and balls). 'FIFA 11+' is time-efficient because it replaces the usual warm-up.

An RCT showed that young female teams performing the 'FIFA $11+$ ' at least twice a week (as a standard warm-up before their training) had 37\% fewer training injuries and 29\% fewer match injuries, and severe injuries were reduced by almost $50 \% .^{20}$ Compliance with 'FIFA 11+' was high, and players with a higher compliance had a significantly lower injury risk than others. $^{34}$

In another RCT study on Canadian youth female football, Steffen $e t a l^{35}$ found that players with higher adherence to 'FIFA 11+' showed significant improvements in functional balance and reduced injury risk. Two recent studies in Italian amateur football players showed that the physiological warm-up effects of 'FIFA 11+' are similar to or even better than a standard warm-up routine, and that it enhances neuromuscular control (core/lower extremity) and knee flexor strength. ${ }^{36} 37$

Other authors have found improvements in static/dynamic balance, and thigh muscle strength in male football and futsal players after performing 'FIFA $11+{ }^{38-41}$

\section{Development of a dissemination strategy}

For F-MARC, the coach is the key person to promote injury prevention to his/her players. While the coach, especially at a low level, has to regard various aspects in the training (eg, physical preparation, tactics, fair play, team success), it is important to raise his/her motivation to implement an injury-prevention programme with his team. It is important to stress that regular and correct performance of the exercises is crucial for the preventive effect.

Information material on 'FIFA 11+' was developed, produced and made available for coaches and players. The material includes a detailed manual, an instructional DVD, a poster, a website and a promotional booklet with DVD. All material is available in the four FIFA languages (English, Spanish, German and French) and can be accessed on http://www.F-MARC.com/11plus.

'FIFA $11+$ ' is best taught to coaches in a workshop that includes theoretical background knowledge and practical demonstration of the exercises as recently shown by Steffen et $a l^{42}$ In a cluster randomised trial on different implementation strategies, the authors found that a preseason coach education workshop was more effective in terms of better compliance and decreased injury risk in players than other delivery methods (unsupervised website, additional supervision by a physical therapist) of the programme. After increasing the motivation of the coach and raising awareness of injury prevention, the exercises should be briefly explained and demonstrated. It is helpful to select a participant to perform the exercise, while the instructor highlights the correct execution of the exercises. The participants should then perform the exercises and be corrected by the instructor(s). The participants should get 'a feeling' for the exercises and appreciate the challenges behind each exercise. In the second half of the workshop, each of the participants should teach at least one of the exercises to the group and get feedback on this from the instructor.

For the countrywide campaign in Switzerland, 'The 11' was integrated with the coach education of the Swiss Football Association (Schweizerischer Fussballverband (SFV)) using a 'teach the teacher' strategy. All instructor coaches of the SFV were educated by sports physical therapists on how to deliver the programme to the coaches in their licensing or refresher courses. During a period of 3 years, 5000 licensed amateur coaches were subsequently instructed on how to perform 'The 11 ' with their teams and received the information material. ${ }^{29}$ The same strategy was used in New Zealand, where 'The 11' was implemented as part of the 'SoccerSmart Program'. ${ }^{28} 43$

\section{Worldwide dissemination of 'FIFA 11+'}

In 2009, FIFA started the dissemination of 'FIFA 11+' in its 209 Member Associations (MAs). On the basis of the experience with the countrywide implementation in Switzerland and New Zealand, and on the evaluations of other sports injuryprevention programme implementations (ie, rugby), ${ }^{44}$ a guideline on how to implement the 'FIFA 11+' injuryprevention programme on a larger scale in amateur football was developed (see figure 1). The implementation is conducted either in close cooperation with MAs or via FIFA Coaching Instructor courses.

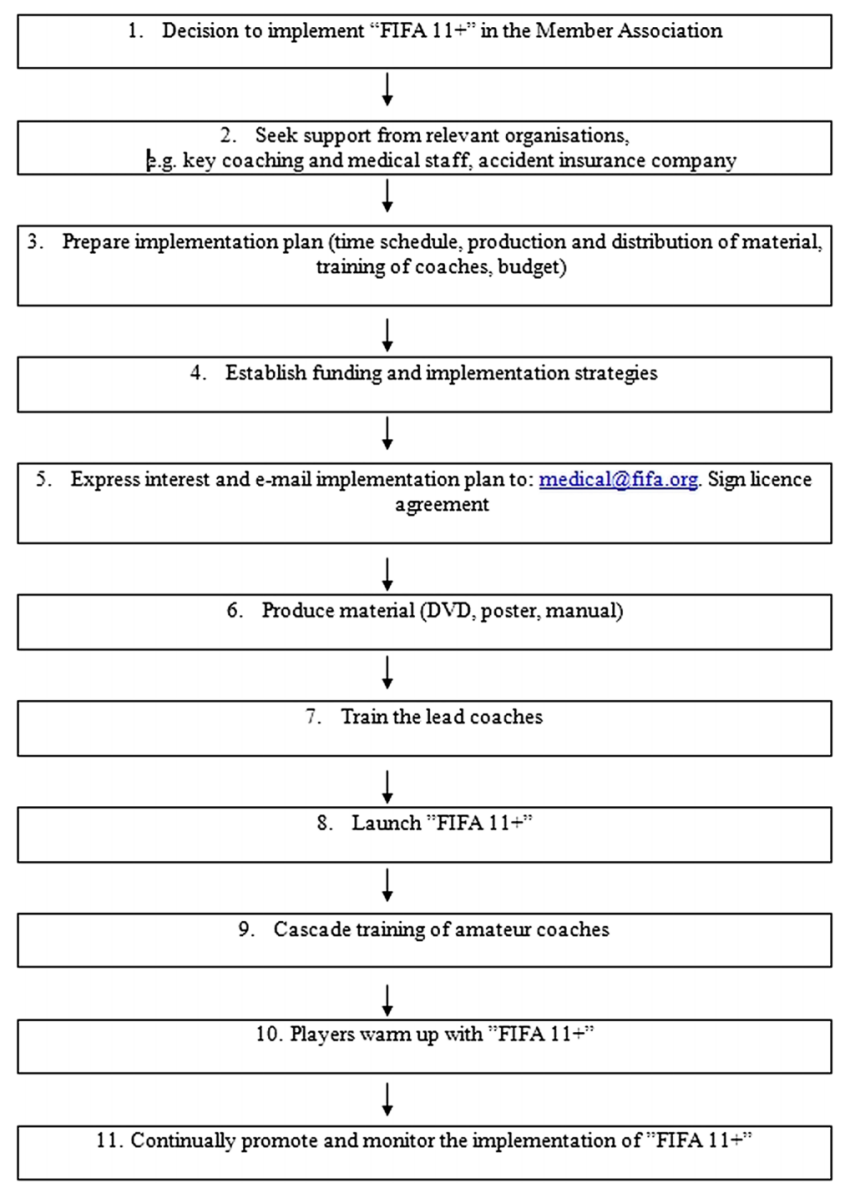

Figure 1 Eleven steps to implement 'FIFA 11+'. 


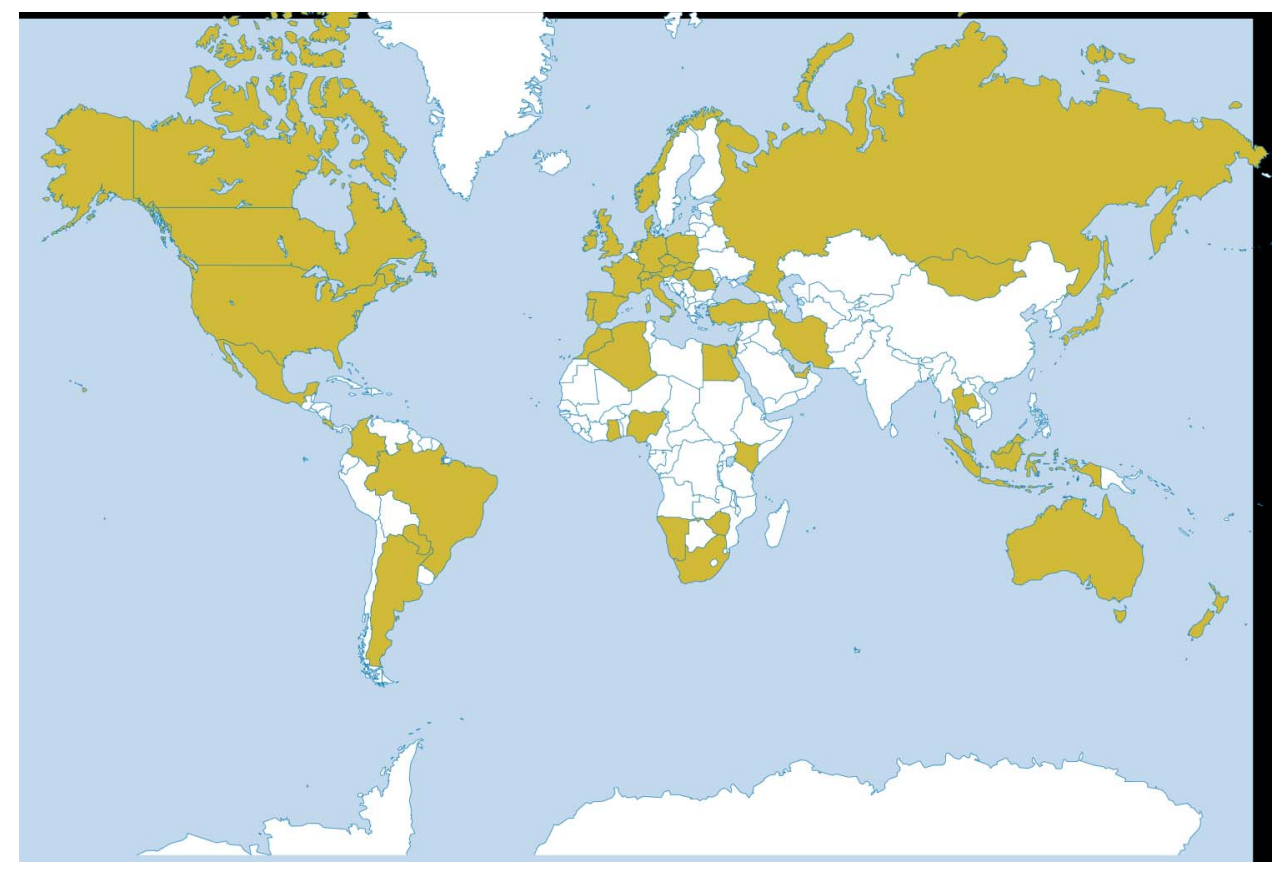

Figure 2 The countries in the dark colour are the ones whose coaches attended a 'FIFA 11+' instructor course (2008-2012).

The national Football Associations of Spain, Japan, Italy, Brazil and Germany integrated 'FIFA 11+' in their coaching curriculum or in their physical training/education curriculum. Thus, the world football champions took the lead and acted as role models, and other MAs (Costa Rica, Hong Kong, Netherlands, Denmark, Poland, Hungary, Australia, England and Thailand) followed and signed the Licence Agreement with FIFA (see figure 1, step 5). Until now about 5000 coaches from more than forty countries have been instructed on how to implement the 'FIFA 11+' (figure 2). Even if this represents just about $25 \%$ of FIFA's MAs and a much lower percentage of all football coaches, it is an important step for the worldwide dissemination of the programme. F-MARC supports MAs in the preparation of educational material in the local language, as well as workshops for the first group of instructors to initiate the cascade training.

\section{Lessons learnt}

The F-MARC team has gained experience during the years of dissemination of the injury-prevention programmes. It has been found that understanding the coach's character and highlighting the importance of the programme to the coach is especially important. Preventing injuries and thereby reducing the number of injured players means that the coach will have more players available for his/her ideal team. Therefore, it is not only information and education about the role of injury prevention that is important, but also speaking the same language as the coach. One of the keys while conducting a course is of 'proposing' rather than 'imposing' 'FIFA 11+'. The dialogue on the pitch with coaches is often more important than the distributed materials, thus allowing for friendly discussion and practical work with the preventive programme. Therefore, the choice of the instructors is crucial and F-MARC's best experiences have been with sports physiotherapists or athletic trainers who have an active involvement in football, because they already 'live and speak the football language'. Additionally, the cooperation with famous players and coaches acting as 'FIFA 11+' ambassadors (see teaser on https://vimeo.com/45562029 and http://www. f-marc.com/11plus) has helped significantly in the communication with coaches. 'FIFA 11+' has also been presented to the delegates of all MAs at the last two FIFA Medical Conferences (Zürich 2009, Budapest 2012). After initial enthusiasm from the interested MAs, F-MARC has experienced a wide range of dedication and compliance from those MAs to the proposed 'FIFA $11+$ ' implementation guidelines. At the MA level, it has to be acknowledged that highly motivated people are needed in order to successfully plan, realise and constantly monitor a countrywide implementation.

\section{Conclusions and future directions}

The two countrywide campaigns in Switzerland and New Zealand represent successful examples of injury prevention in amateur football. ${ }^{28}{ }^{29}$ Gianotti and Hume ${ }^{46}$ introduced preimplementation and postimplementation cost outcome formulae to provide information regarding the success of a prevention programme. These data provide a return on investment for each dollar invested in the programme and cost-savings. Since the SoccerSmart Programme (including the 'The 11' programme) was introduced in New Zealand in 2004, the Accident Compensation Corporation (ACC) has invested NZ\$650 000. Until June 2011, ACC has saved NZ\$5 331000 : the return of investment has risen to 8.20 for each invested Dollar (personal communication of Dr S Gianotti, ACC, New Zealand). These data, together with the published results of the countrywide implementation in Switzerland, reinforce the hypothesis outlined by F-MARC back in 1994: prevention measures or programmes can not only reduce the incidence of football injuries, but also have the potential to save billions of dollars in health-related costs worldwide. ${ }^{47}$

In the next years, FIFA and F-MARC will continue the worldwide dissemination of 'FIFA 11+', with particular attention in seeking the best possible cooperation with MAs adopting the 'FIFA $11+$ ' injury-prevention programme. 


\section{What this paper adds}

- A guideline on the steps necessary to implement a countrywide injury-prevention programme ('FIFA 11+') in amateur football.

- A better understanding of the role of the football coach as the key person in the implementation process.

- Prevention in community football not only reduces the injury incidence but also has a socioeconomic impact in terms of healthcare costs reduction.

Contributors All authors contributed to the concept, design and writing of the manuscript.

\section{Competing interests None.}

Provenance and peer review Not commissioned; externally peer reviewed.

Open Access This is an Open Access article distributed in accordance with the Creative Commons Attribution Non Commercial (CC BY-NC 3.0) license, which permits others to distribute, remix, adapt, build upon this work non-commercially, and license their derivative works on different terms, provided the original work is properly cited and the use is non-commercial. See: http://creativecommons.org/ licenses/by-nc/3.0/

\section{REFERENCES}

1 FIFA. Big Count 2006. http://www.fifa.com/worldfootball/bigcount/ (cited 21 Feb 2013).

2 SUVA. Ball Sport Statistics. http://www.suva.ch/startseite-suva/praevention-suva/ sichere-freizeit-suva/kampagne-ballsport-fitness-suva/statistik-ballsport-suva.htm. http://www.suva.ch/startseite-suva/praevention-suva/sichere-freizeit-suva/ kampagne-ballsport-fitness-suva/statistik-ballsport-suva.htm

3 Agel J, Evans TA, Dick R, et al. Descriptive epidemiology of collegiate men's soccer injuries: National Collegiate Athletic Association Injury Surveillance System, 19881989 through 2002-2003. J Athl Train 2007;42:270-7.

4 Dick R, Putukian M, Agel J, et al. Descriptive epidemiology of collegiate women's soccer injuries: National Collegiate Athletic Association Injury Surveillance System, 1988-1989 through 2002-2003. J Athl Train 2007;42:278-85.

5 Ekstrand J, Hagglund $M$, Walden M. Injury incidence and injury patterns in professional football: the UEFA injury study. Br J Sports Med 2011;45:553-8.

6 Giza E, Micheli LJ. Soccer injuries. Med Sport Sci 2005;49:140-69.

7 Junge A, Dvorak J. Soccer injuries: a review on incidence and prevention. Sports Med 2004;34:929-38.

8 Emery CA, Meeuwisse WH. The effectiveness of a neuromuscular prevention strategy to reduce injuries in youth soccer: a cluster-randomised controlled trial. $\mathrm{Br} J$ Sports Med 2010;44:555-62.

9 Engebretsen AH, Myklebust G, Holme I, et al. Prevention of injuries among male soccer players: a prospective, randomized intervention study targeting players with previous injuries or reduced function. Am I Sports Med 2008;36:1052-60.

10 Gilchrist J, Mandelbaum BR, Melancon H, et al. A randomized controlled trial to prevent noncontact anterior cruciate ligament injury in female collegiate soccer players. Am J Sports Med 2008;36:1476-83.

11 Hagglund $\mathrm{M}$, Walden $\mathrm{M}$, Ekstrand J. Lower reinjury rate with a coach-controlled rehabilitation program in amateur male soccer: a randomized controlled trial. Am J Sports Med 2007;35:1433-42.

12 Heidt RS Jr., Sweeterman LM, Carlonas RL, et al. Avoidance of soccer injuries with preseason conditioning. Am J Sports Med 2000;28:659-62.

13 Junge $A$, Rosch D, Peterson L, et al. Prevention of soccer injuries: a prospective intervention study in youth amateur players. Am J Sports Med 2002;30:652-9.

14 Kiani A, Hellquist E, Ahlqvist K, et al. Prevention of soccer-related knee injuries in teenaged girls. Arch Intern Med 2010;170:43-9.

15 LaBella CR, Huxford MR, Grissom J, et al. Effect of neuromuscular warm-up on injuries in female soccer and basketball athletes in urban public high schools: cluster randomized controlled trial. Arch Pediatr Adolesc Med 2011;165:1033-40.

16 Mandelbaum BR, Silvers HJ, Watanabe DS, et al. Effectiveness of a neuromuscular and proprioceptive training program in preventing anterior cruciate ligament injuries in female athletes: 2-year follow-up. Am I Sports Med 2005;33:1003-10.

17 Mohammadi F. Comparison of 3 preventive methods to reduce the recurrence of ankle inversion sprains in male soccer players. Am J Sports Med 2007;35:922-6.

18 Sharpe SR, Knapik J, Jones B. Ankle braces effectively reduce recurrence of ankle sprains in female soccer players. J Athl Train 1997;32:21-4.
19 Soderman K, Werner S, Pietila T, et al. Balance board training: prevention of traumatic injuries of the lower extremities in female soccer players? A prospective randomized intervention study. Knee Surg Sports Traumatol Arthrosc 2000;8:356-63.

20 Soligard T, Myklebust G, Steffen K, et al. Comprehensive warm-up programme to prevent injuries in young female footballers: cluster randomised controlled trial. BMJ 2008;337:a2469.

21 Surve I, Schwellnus MP, Noakes T, et al. A fivefold reduction in the incidence of recurrent ankle sprains in soccer players using the Sport-Stirrup orthosis. Am J Sports Med 1994;22:601-6.

22 Tropp H, Askling C, Gillquist J. Prevention of ankle sprains. Am J Sports Med 1985;13:259-62.

23 Van Beijsterveldt AM, Van de Port IG, Krist MR, et al. Effectiveness of an injury prevention programme for adult male amateur soccer players: a cluster-randomised controlled trial. Br J Sports Med 2012;46:1114-18.

24 Walden M, Atroshi I, Magnusson $\mathrm{H}$, et al. Prevention of acute knee injuries in adolescent female football players: cluster randomised controlled trial. BMJ 2012;344:e3042.

25 Gatterer H, Ruedl G, Faulhaber M, et al. Effects of the performance level and the FIFA "11" injury prevention program on the injury rate in Italian male amateur soccer players. I Sports Med Phys Fitness 2012;52:80-4.

26 Finch C. A new framework for research leading to sports injury prevention. J Sci Med Sport 2006;9:3-9.

27 Finch CF. No longer lost in translation: the art and science of sports injury prevention implementation research. Br I Sports Med 2011;45:1253-7.

28 Dick R, Gaulet C, Gianotti S. Implementing large-scale injury prevention programs. In: Bahr R, Engebretsen L, eds. Sports Injury prevention. Chichester: Wiley-Blackwell, 2009:197-211.

29 Junge $A$, Lamprecht $M$, Stamm $H$, et al. Countrywide campaign to prevent soccer injuries in Swiss amateur players. Am J Sports Med 2011;39:57-63.

30 Ekstrand J, Gillquist J, Liljedahl SO. Prevention of soccer injuries. Supervision by doctor and physiotherapist. Am J Sports Med 1983;11:116-20.

31 Caraffa A, Cerulli G, Projetti M, et al. Prevention of anterior cruciate ligament injuries in soccer. A prospective controlled study of proprioceptive training. Knee Surg Sports Traumatol Arthrosc 1996;4:19-21.

32 Steffen $\mathrm{K}$, Myklebust $\mathrm{G}$, Olsen $\mathrm{OE}$, et al. Preventing injuries in female youth footballa cluster-randomized controlled trial. Scand J Med Sci Sports 2008;18:605-14.

33 Hewett TE, Lindenfeld TN, Riccobene JV, et al. The effect of neuromuscular training on the incidence of knee injury in female athletes. A prospective study. Am J Sports Med 1999;27:699-706.

34 Soligard T, Nilstad A, Steffen K, et al. Compliance with a comprehensive warm-up programme to prevent injuries in youth football. Br I Sports Med 2010;44:787-93.

35 Steffen $\mathrm{K}$, Emery CA, Romiti $\mathrm{M}$, et al. High adherence to a neuromuscular injury prevention programme (FIFA 11+) improves functional balance and reduces injury risk in Canadian youth female football players: a cluster randomised trial. $\mathrm{Br} J$ Sports Med 2013;47:794-802.

36 Bizzini M, Impellizzeri F, Dvorak J, et al. Physiological and performance responses to the FIFA 11+ (part 2): is it a good warm up? I Sports Sci in press.

37 Impellizzeri F, Bizzini M, Dvorak J, et al. Physiological and performance responses to the FIFA 11+ (part 1): a randomized controlled trial on the training effects. I Sports Sci in press.

38 Daneshjoo A, Mokhtar AH, Rahnama N, et al. The effects of comprehensive warm-up programs on proprioception, static and dynamic balance on male soccer players. PloS ONE 2012;7:e51568.

39 Daneshjoo A, Mokhtar AH, Rahnama N, et al. The effects of injury preventive warm-up programs on knee strength ratio in young male professional soccer players. PloS ONE 2012;7:e50979.

40 Reis I, Rebelo A, Krustrup P, et al. Performance enhancement effects of Federation Internationale de Football Association's "The 11+" Injury Prevention Training Program in Youth Futsal Players. Clin I Sport Med 2013.

41 Brito J, Figueiredo P, Fernandes L, et al. Isokinetic strength effects of FIFA's "The $11+"$ injury prevention training programme. Isokinetics Exerc Sci 2010;18:211-15.

42 Steffen K, Meeuwisse WH, Romiti M, et al. Evaluation of how different implementation strategies of an injury prevention programme (FIFA 11+) impact team adherence and injury risk in Canadian female youth football players: a clusterrandomised trial. Br J Sports Med 2013;47:480-7.

43 Gianotti S, Hume PA, Tunstall H. Efficacy of injury prevention related coach education within netball and soccer. J Sci Med Sport 2010;13:32-5.

44 Chalmers DJ, Simpson JC, Depree R. Tackling Rugby injury: lessons learned from the implementation of a five-year sports injury prevention program. J Sci Med Sport 2004;7:74-84.

45 Gianotti SM, Quarrie KL, Hume PA. Evaluation of RugbySmart: a rugby union community injury prevention programme. J Sci Med Sport 2009;12:371-5.

46 Gianotti S, Hume PA. A cost-outcome approach to pre and post-implementation of national sports injury prevention programmes. J Sci Med Sport 2007;10:436-46.

47 Dvorak J. Give Hippocrates a jersey: promoting health through football/sport. $\mathrm{Br} J$ Sports Med 2009;43:317-22. 